NASA/TM-2006-214411

AIAA-2006-4436

\title{
Settled Cryogenic Propellant Transfer
}

Bernard F. Kutter, Frank Zegler, Steve Sakla, John Wall, and Josh Hopkins

Lockheed Martin Space Systems Company, Denver, Colorado

Greg Saks and Jack Duffey

Lockheed Martin Space Systems Company, Huntsville, Alabama

David J. Chato

Glenn Research Center, Cleveland, Ohio 


\section{NASA STI Program . . . in Profile}

Since its founding, NASA has been dedicated to the advancement of aeronautics and space science. The NASA Scientific and Technical Information (STI) program plays a key part in helping NASA maintain this important role.

The NASA STI Program operates under the auspices of the Agency Chief Information Officer. It collects, organizes, provides for archiving, and disseminates NASA's STI. The NASA STI program provides access to the NASA Aeronautics and Space Database and its public interface, the NASA Technical Reports Server, thus providing one of the largest collections of aeronautical and space science STI in the world. Results are published in both non-NASA channels and by NASA in the NASA STI Report Series, which includes the following report types:

- TECHNICAL PUBLICATION. Reports of completed research or a major significant phase of research that present the results of NASA programs and include extensive data or theoretical analysis. Includes compilations of significant scientific and technical data and information deemed to be of continuing reference value. NASA counterpart of peer-reviewed formal professional papers but has less stringent limitations on manuscript length and extent of graphic presentations.

- TECHNICAL MEMORANDUM. Scientific and technical findings that are preliminary or of specialized interest, e.g., quick release reports, working papers, and bibliographies that contain minimal annotation. Does not contain extensive analysis.

- CONTRACTOR REPORT. Scientific and technical findings by NASA-sponsored contractors and grantees.
- CONFERENCE PUBLICATION. Collected papers from scientific and technical conferences, symposia, seminars, or other meetings sponsored or cosponsored by NASA.

- SPECIAL PUBLICATION. Scientific, technical, or historical information from NASA programs, projects, and missions, often concerned with subjects having substantial public interest.

- TECHNICAL TRANSLATION. Englishlanguage translations of foreign scientific and technical material pertinent to NASA's mission.

Specialized services also include creating custom thesauri, building customized databases, organizing and publishing research results.

For more information about the NASA STI program, see the following:

- Access the NASA STI program home page at http://www.sti.nasa.gov

- E-mail your question via the Internet to help@sti.nasa.gov

- Fax your question to the NASA STI Help Desk at 301-621-0134

- Telephone the NASA STI Help Desk at 301-621-0390

- Write to:

NASA STI Help Desk

NASA Center for AeroSpace Information 7121 Standard Drive Hanover, MD 21076-1320 
NASA/TM-2006-214411

AIAA-2006-4436

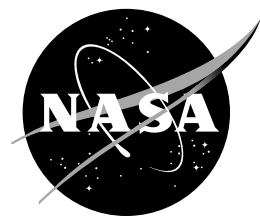

\section{Settled Cryogenic Propellant Transfer}

Bernard F. Kutter, Frank Zegler, Steve Sakla, John Wall, and Josh Hopkins

Lockheed Martin Space Systems Company, Denver, Colorado

Greg Saks and Jack Duffey

Lockheed Martin Space Systems Company, Huntsville, Alabama

David J. Chato

Glenn Research Center, Cleveland, Ohio

Prepared for the

42nd Joint Propulsion Conference and Exhibit

cosponsored by the AIAA, ASME, SAE, and ASEE

Sacramento, California, July 9-12, 2006

National Aeronautics and

Space Administration

Glenn Research Center

Cleveland, Ohio 44135 
Trade names and trademarks are used in this report for identification only. Their usage does not constitute an official endorsement, either expressed or implied, by the National Aeronautics and Space Administration.

Level of Review: This material has been technically reviewed by technical management.

Available from

NASA Center for Aerospace Information 7121 Standard Drive

Hanover, MD 21076-1320
National Technical Information Service 5285 Port Royal Road Springfield, VA 22161 


\title{
Settled Cryogenic Propellant Transfer
}

\author{
Bernard F. Kutter, Frank Zegler, Steve Sakla, John Wall, Greg Saks, Jack Duffey, and Josh Hopkins \\ Lockheed Martin Space Systems Company \\ Denver, Colorado 80201 \\ Greg Saks and Jack Duffey \\ Lockheed Martin Space Systems Company \\ Huntsville, Alabama 35807 \\ David Chato \\ National Aeronautics and Space Administration \\ Glenn Research Center \\ Cleveland, Ohio 44135
}

\begin{abstract}
Cryogenic propellant transfer can significantly benefit NASA's space exploration initiative. LMSSC parametric studies indicate that "Topping off" the Earth Departure Stage (EDS) in LEO with 20 mT of additional propellant using cryogenic propellant transfer increases the lunar delivered payload by $5 \mathrm{mT}$. Filling the EDS to capacity in LEO with $78 \mathrm{mT}$ of propellants increases the delivered payload by $20 \mathrm{mT}$. Cryogenic propellant transfer is directly extensible to Mars exploration in that it provides propellant for the Mars Earth Departure stage and in-situ propellant utilization at Mars.

To enable the significant performance increase provided by cryogenic propellant transfer, the reliability and robustness of the transfer process must be guaranteed. By utilizing low vehicle acceleration during the cryogenic transfer the operation is significantly simplified and enables the maximum use of existing, reliable, mature upper stage cryogenic-fluid-management (CFM) techniques. Due to settling, large-scale propellant transfer becomes an engineering effort, and not the technology development endeavor required with zero-gravity propellant transfer. The following key CFM technologies are all currently implemented by settling on both the Centaur and Delta IV upper stages: propellant acquisition, hardware chilldown, pressure control, and mass gauging. The key remaining technology, autonomous rendezvous and docking, is already in use by the Russians, and must be perfected for NASA whether the use of propellant transfer is utilized or not.
\end{abstract}

\section{Nomenclature}

CaLV Cargo launch vehicle ( $>100 \mathrm{mT}$ class)

CEV Crew Exploration Vehicle

CLV Crew Launch Vehicle

EDS Earth Departure Stage

g Earth's Gravity

LAD Liquid Acquisition Device

LEO Low Earth Orbit

LOI Lunar Orbit Insertion

LSAM Lunar Surface Access Module

PMD Propellant Management Device

SM Service Module

TEI Trans Earth Injection 


\section{Introduction}

In January 2004 President Bush announced a new vision for NASA's Space Exploration Program. He challenged America to return to the moon, and explore worlds beyond our own. In response, NASA developed a baseline lunar exploration architecture (ref. 1) centered on the launch of a CaLV and CLV with LEO rendezvous (fig. 1).

\section{ESAS Baseline Architecture}

The ESAS baseline exploration architecture utilizes the CaLV to launch the EDS and LSAM. This architecture requires the EDS to burn $\sim 45$ percent of its $170 \mathrm{mT}$ of $\mathrm{LO}_{2}$ and $\mathrm{LH}_{2}$ to achieve Earth orbit. Following rendezvous with the CEV, the EDS completes a second burn sending the LSAM and CEV on their trajectory to the moon.

The use of the EDS to achieve Earth orbit and accelerate the stack to Earth departure velocity results in a stage that is much heavier than if it were sized strictly to complete the Earth departure burn starting in LEO. This oversized stage also provides a sizeable side wall profile, absorbing significantly more heat then a smaller stage would. This heating increases propellant boil-off during the up to 95 days of on-orbit waiting for the launch of the CEV.

\section{Benefit of Topping Off the Earth Departure Stage}

The oversized EDS provides NASA's exploration architecture with an excellent opportunity to significantly increase the lunar delivered payload, or alternatively reduce the CaLV payload requirement. Through the use of cryogenic propellant transfer, NASA could top off the EDS in LEO. Following the LEO insertion burn, the EDS retains $\sim 92 \mathrm{mT}$ of its $170 \mathrm{mT}$ propellant capacity (ref. 2). After the LEO burn, the EDS could be filled with up to an additional $78 \mathrm{mT}$ of propellant.

"Topping off" the EDS with $\sim 20 \mathrm{mT}$ in LEO, using cryogenic propellant transfer, increases the useful, lunar delivered payload by $5 \mathrm{mT}$ (fig. 2). Filling the EDS to capacity in LEO with $78 \mathrm{mT}$ increases the delivered payload by over $20 \mathrm{mT}$.

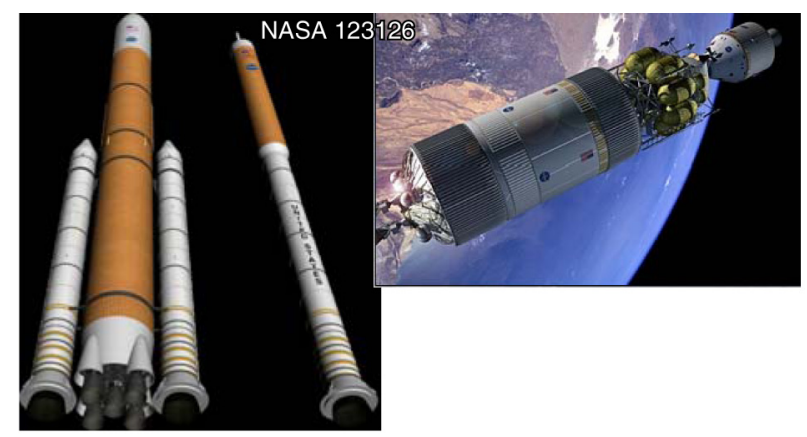

Figure 1.-The ESAS baseline architecture consists of the launch of the EDS and LSAM with a CaLV followed by the CEV launch on a CLV. 


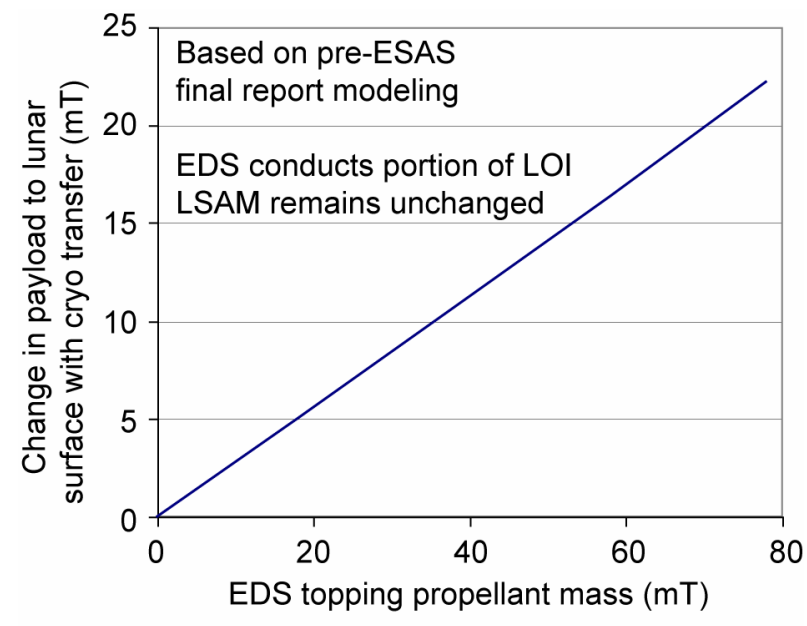

Figure 2.-Topping off the EDS results in a tremendous increase of lunar delivered payload.

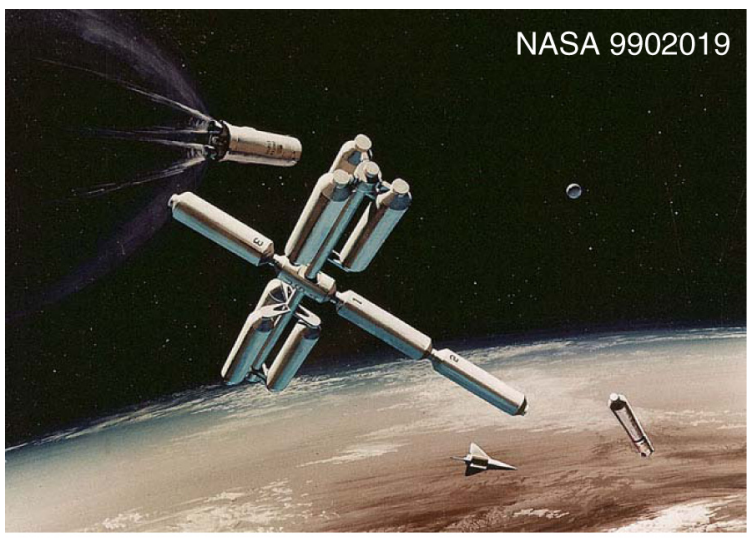

Figure 3.-Permanent space based propellant depot.

\section{Cryogenic Propellant Transfer Made Easy}

Typically, cryogenic propellant transfer has been synonymous with zero-g propellant depots (fig. 3). Large scale cryogenic depots envisioned as refueling stations for robust exploration are sufficiently massive that operations must be conducted in a zero-g environment. Transferring cryogenic propellants in zero-g places significant technological hurdles on propellant transfer, such as: zero-g mass gauging, propellant acquisition, and pressure control (table I). This ideal cryogenic propellant transfer is frequently coupled with the desire for zero boil-off and zero vent fill. Although admirable goals, these "ideal" propellant transfer features have erected technological barriers that have successfully blocked the implementation of cryogenic propellant transfer, and prevented realization of the enormous benefits that propellant transfer offers.

Utilizing acceleration during the cryogenic propellant transfer procedure significantly simplifies the operation by enabling the maximum use of existing, mature upper stage cryogenic-fluid-management (CFM) techniques. With settling, large-scale propellant transfer becomes an engineering effort, not a technology development endeavor. The key technologies: propellant acquisition, hardware chilldown, 


TABLE I.-SETTLED CRYOGENIC PROPELLANT
TRANSFER CAN BENEFIT FROM THE VAST
CFM EXPERIENCE USED ON CENTAUR
AND OTHER CRYOGENIC UPPERSTAGES
\begin{tabular}{|l|c|c|}
\hline \multicolumn{2}{|c|}{ Cryo transfer technology } & \multicolumn{2}{|c|}{ TRL } \\
\hline \multicolumn{2}{|c|}{ Cretled $^{\mathrm{a}}$} & Setted \\
\hline System chilldown & 8 & 8 \\
\hline Propellant acquisition & 3 & 9 \\
\hline Passive long duration storage & 5 & 5 \\
\hline Ullage and liquid stratification & 3 & 9 \\
\hline Propellant expulsion efficiency & 3 & 8 \\
\hline Mass gauging & 3 & 9 \\
\hline Pressure control & 4 & 9 \\
\hline Fluid coupling & 6 & 6 \\
\hline AR\&D & 6 & 6 \\
\hline Transfer system operation & 3 & 6 \\
\hline aref. 6 & &
\end{tabular}

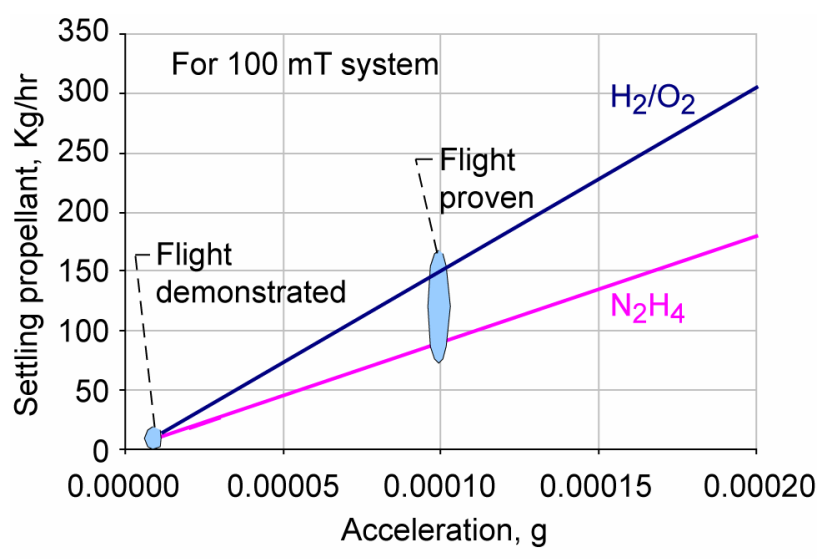

Figure 4.-With low acceleration, propellant consumption for settled cryogenic propellant transfer is reasonable.

pressure control, and mass gauging are all currently in use on the Atlas V Centaur and the Delta IV upper stage. The key remaining technology, rendezvous and docking is required regardless of the use of propellant transfer.

Historically, settled propellant transfer between vehicles has been ruled out because of the assumed large quantity of propellant required for settling. However, at sufficiently low settling levels this settling propellant becomes manageable (fig. 4). For a representative $100 \mathrm{mT}$ system, settling consumes $100 \mathrm{lb} / \mathrm{hr}$ of settling propellant, at $10^{-4} \mathrm{~g}$. At $10^{-5} \mathrm{~g}$ this settling consumption decreases to $10 \mathrm{lb} / \mathrm{hr}$. This settling propellant could easily consist of warm vented $\mathrm{GH}_{2}$ and $\mathrm{GO}_{2}$ extracted from the EDS for pressure control during the propellant transfer process.

\section{Key Enabling Technologies}

The enabling technologies allowing implementation of cryogenic propellant transfer are currently in use on existing cryogenic, multi-burn stages. A partial list of relevant CFM capabilities that have been demonstrated on Centaur is provided in table II. 


TABLE II.-CENTAUR HAS CONDUCTED NUMEROUS
CFM FLIGHT DEMONSTRATIONS RELEVANT TO
CRYOGENIC PROPELLANT TRANSFER
\begin{tabular}{|l|l|}
\hline Liquid control $\left(10^{-5}\right.$ to $6 \mathrm{~g}$ 's $)$ & Long coast (to $17 \mathrm{hr})$ \\
\hline System warming and chilldown & Pressurization sequencing \\
\hline Propellant acquisition & Slosh characterization \\
\hline System thermal interaction & Vent sequencing \\
\hline Ullage and liquid stratification & Pressure collapse \\
\hline Propellant utilization & Bubbler vs. Ullage Pressn. \\
\hline Mass gauging & Unbalanced venting \\
\hline
\end{tabular}

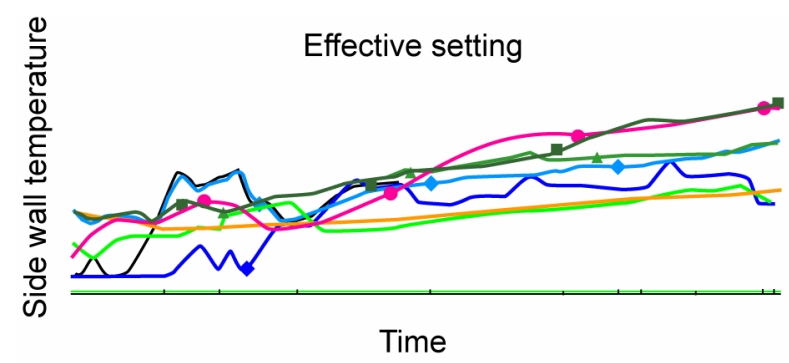

Figure 5.-Centaur has demonstrated effective propellant control at 10-5 G's, well below the acceleration required to make settled propellant transfer attractive.

\section{Low Acceleration Settling}

Over the past 15 years, Centaur has spearheaded the development of ultra low settling for CFM. Centaur has reduced the standard parking orbit coast settling from $10^{-3}$ to $2 \times 10^{-4} \mathrm{~g}$ for short coast missions; realizing a significant performance enhancement, while maintaining adequate propellant control. For intermediate coast durations between $20 \mathrm{~min}$ and $2 \mathrm{hr}$, Centaur has further reduced the settling acceleration to $8 \times 10^{-5} \mathrm{~g}$ 's.

In the quest for even more performance, Centaur has demonstrated effective propellant control at accelerations down to $10^{-5} \mathrm{~g}$ (fig. 5). Similarly, in the 1960s Saturn (ref. 10) also demonstrated effective settling at $2 \times 10^{-5} \mathrm{~g}$.

\section{Propellant Acquisition}

Propellant acquisition through settling has been used reliably for all large scale cryogenic upper stages. Expulsion efficiencies well in excess of 99.5 percent of liquids are achieved on Centaur, even at the relatively low accelerations encountered during pre-start and blowdown. Expulsion efficiency at $10^{-5} \mathrm{~g}$ is yet to be demonstrated.

With settled operations, expulsion efficiency is further increased by the ability to maintain a warm ullage. Settling effectively separates the liquid and gas in a tank enabling the ullage to remain warm during the expulsion process. By allowing the ullage to remain warm, there is the potential to increase total expulsion efficiency by $\sim 0.9$ percent (fig. 6 ). 


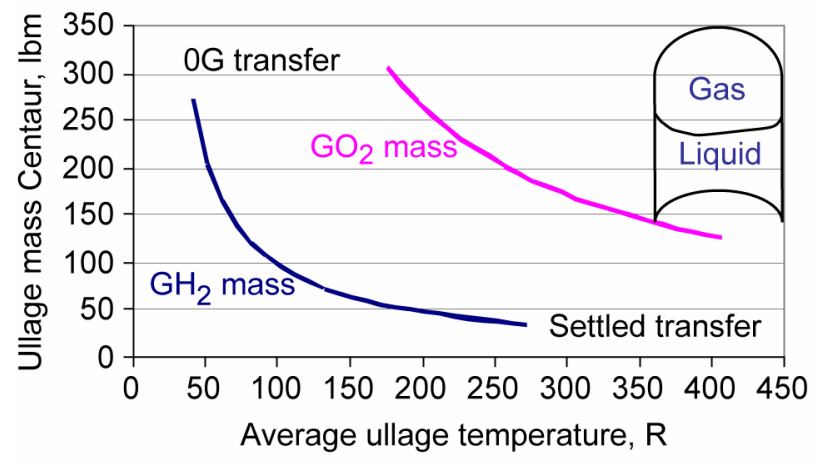

Figure 6.-Low acceleration effectively separates the ullage and liquid enabling pure gas venting while reducing the gaseous residuals.
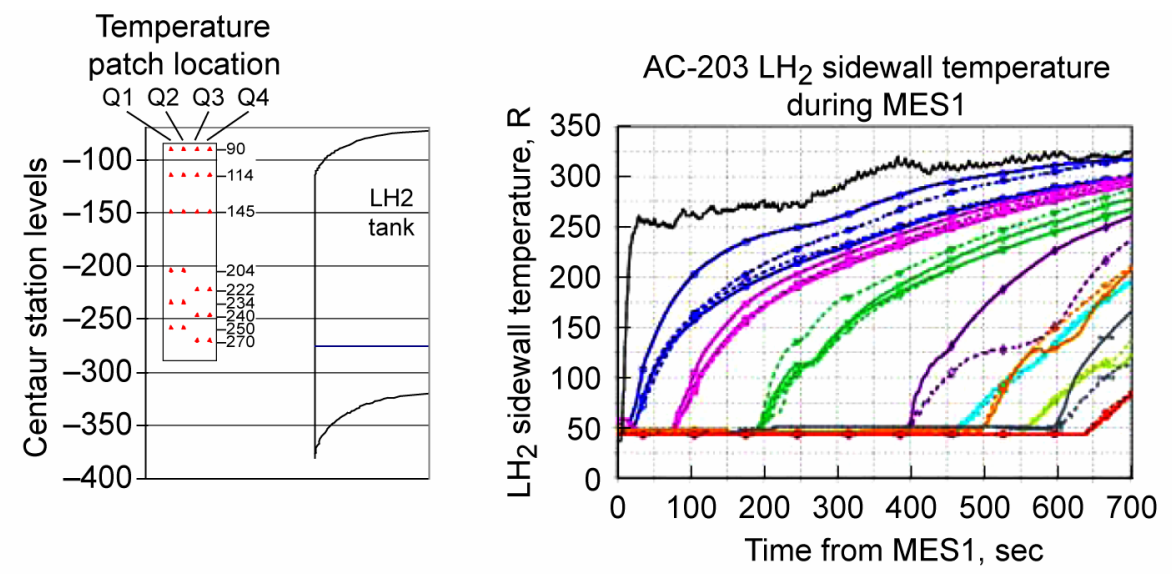

Figure 7.-Centaur externally mounted thermal couples effectively measure liquid level.

\section{System Chilldown}

The Centaur upper stage has demonstrated highly efficient hardware chilldown procedures that are directly applicable to cryogenic transfer. Chilldown of ducting, tank walls and the engine have been demonstrated with multiple alternate chilldown procedures. Chilldown effectiveness using full, trickle, and pulse $\mathrm{LH}_{2}$ and $\mathrm{LO}_{2}$ flow has been demonstrated in the low $\mathrm{g}$ space environment. Pulse chilldown has proven to be especially effective at chilling down the feed lines and engine due to the ability to gain the full benefit of the heat of vaporization and vapor expansion cooling.

\section{Mass Gauging}

With settling, mass gauging can be accomplished using numerous accurate and reliable techniques. Measuring the acceleration achieved with a known settling thrust provides a simple method that accurately gauges total system mass. Thermal couples and liquid sensors internal to the tank, or mounted to the outside of a thin walled tank have proven very effective in defining the station level of the liquid/gas interface (fig. 7). The cryo tracker (refs. 3 and 11) concept promises a simple robust system for accurate liquid surface gauging at low acceleration. At the higher accelerations realized during a burn, tank head pressure has proven to be very effective at measuring liquid mass, ensuring $>99.9$ percent relative $\mathrm{LO}_{2} / \mathrm{LH}_{2}$ propellant expulsion efficiency for Centaur. Understanding the propellant mass during 
the high acceleration environment during a burn can be coupled with book keeping propellant vented during a coast to provide an accurate understanding of the propellant remaining in the tank. All of the above methods other than cryo tracker, have been successfully used on Centaur during actual flights to understand the quantity of $\mathrm{LH}_{2}$ and $\mathrm{LO}_{2}$ remaining in the tanks.

\section{Pressure Control}

Low-g settling provides a flight proven, reliable method to separate liquid and gas (fig. 6). This settling can be continuous for short coast durations, or intermittent, separating long zero-g periods, potentially weeks with adequate tank insulation, for long coasts. This liquid/gas separation enables heat rejection via venting for long coasts and has been demonstrated on 183 Centaur flights, 8 Delta III and IV flights, and 8 Saturn S4B flights. Settled venting results in extremely robust tank heat rejection. This robustness is due to the fact that any localized propellant warm spots, due to penetration or other high heating sources, causes the propellant to boil regardless of the location in a tank. Alternative, zero-g vent systems rely on mechanical mixers to distribute the point cooling during venting. The mixer must ensure complete tank mixing, otherwise localized hot spots will develop resulting in potentially uncontrollable tank pressure.

Similarly, settling allows venting during propellant transfer to maintain pressure in the receiver tank at desired levels. With extremely low acceleration, propellant entering the receiver tank may geyser. To prevent liquid venting, the propellant transfer process may need to be accomplished in pulse mode, where propellant transfer and venting are conducted sequentially.

\section{Long Term Cryogenic Storage}

A recent study on the Centaur indicates how robust passive long term $\mathrm{LO}_{2} / \mathrm{LH}_{2}$ storage can be accomplished (ref. 5). The study shows that efficient passive cryogenic storage for periods up to a year is feasible with proper system design.

\section{Fluid Coupling}

Robust but heavy cryogenic fluid couplings are routinely used for cryogenic launch vehicle tanking. Numerous concepts have been considered for flight capable variants of these ground systems. One option for a cryogenic fluid coupling is derived from the Centaur $\mathrm{LO}_{2}$ feedline slip duct that is currently used on Centaur. This slip duct is a flight proven component that provides the required cryogenic sealing, coupling and decoupling, and high-flow capacity with minimal thermal mass. Development of a coupling that can mate autonomously on-orbit will require significant development.

\section{Centaur Test Bed}

The end to end demonstration of cryogenic propellant transfer can be demonstrated as a low cost, ride share payload on near term Atlas Centaur missions. The Centaur Test Bed (CTB) (ref. 8, fig. 8), is a ride share payload concept that would be mounted to the Centaur aft bulkhead. Following delivery of the primary payload the CTB would then take advantage of the thousands of pounds of residual $\mathrm{LO}_{2}$ and $\mathrm{LH}_{2}$ typical of upcoming Atlas missions to demonstrate the actual fluid coupling, chilldown, transfer and pressure control processes. Such an end to end demonstration could be cost effectively repeated multiple times defining preferred process operations and repeatability. This would set the stage for successful, low risk implementation of large scale cryogenic propellant transfer in support of exploration. Development of the CTB concept was conducted under contract to NASA Glenn (ref. 9). 


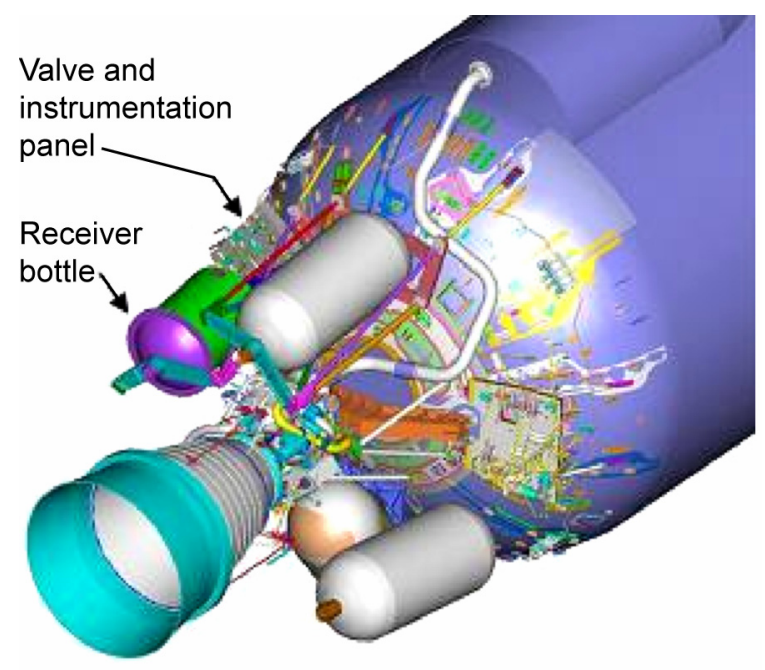

Figure 8.-The Centaur Test Bed (CTB) offers a near term, low cost method to demonstrate in-space cryogenic propellant transfer.

\section{Simplified Stages}

By sizing the EDS sufficiently to accommodate all of the propellant required for a lunar mission, the other transportation elements comprising exploration, LOI, Lunar Descent, Lunar Ascent, and TEI could be designed to be launched empty. Once these elements are on orbit, propellant could be transferred from the EDS into these propulsion stages that are strictly designed to contain propellants in the space environment. By eliminating the need to accommodate propellant during ground operations and launch, these elements could be made significantly lighter by eliminating the foam insulation required while in the atmosphere, and designing the structure for the significantly reduced loads. Weight savings on the LSAM and TEI stages are the most critical since they both are carried through significant delta velocities.

\section{Conclusion}

NASA's current exploration architecture can significantly benefit from the use of on-orbit refueling to increase the lunar delivered payload, or alternatively reduce the CaLV payload requirement. Through the use of cryogenic propellant transfer NASA could top off the EDS in LEO. "Topping off' the EDS with $\sim 20 \mathrm{mT}$ in LEO, using cryogenic propellant transfer, increases the lunar delivered payload by $5 \mathrm{mT}$. Entirely filling the EDS in LEO with $78 \mathrm{mT}$ increases the delivered payload by over $20 \mathrm{mT}$.

Utilizing low level acceleration during the cryogenic propellant transfer procedure significantly simplifies the entire operation, enabling the maximum use of existing, mature upper stage cryogenicfluid-management (CFM) techniques. Settled methodologies for propellant acquisition, hardware chilldown, pressure control and mass gauging are already in service on Atlas V Centaur and Delta IV upper stage. The vital remaining technology, autonomous rendezvous and docking is required regardless of the use of propellant transfer. Although the key CFM technologies have been independently developed and demonstrated, the complete system operation in the space environment must be demonstrated. Near term ride share opportunities, such as CTB, can be used to demonstrate the system functionality of cryogenic propellant transfer. 


\section{References}

1. "NASA's Exploration Systems Architecture Study," Final Report, November 2005, NASA/TM2005-214062, http://www.nasa.gov/pdf/140649main_ESAS_full.pdf

2. Stage and propellant mass were derived from the ESAS final report, reference 1, updated with personal communication with multiple sources at MSFC.

3. Daniel J. Schieb, "Cryo Tracker Mass Gauging System Testing in a Launch Vehicle Simulation," CEC 2005-0830.

4. NASA President's FY 2007 Budget Request, http://t2www.nasa.r3h.net/pdf/142458main_FY07_budget_full.pdf

5. Kutter, B.F. et al., "Atlas Centaur Extensibility to Long-Duration In-Space Applications" AIAA2005-6738, September 2005.

6. Chato, David J., "Flight Development for Cryogenic Fluid Management in Support of Exploration Missions" AIAA-2006-0940, January, 2006.

7. November 16, 2006 Griffin on space commercialization; http://www.cfnews13.com/StoryHeadline.aspx?id=11256

8. Sakla, Steve "Centaur Test Bed (CTB) for Cryogenic Fluid Management," AIAA-2006-4603, July 2006.

9. "Cryogenic Refueling," Contract Number NNC05QA89P, October 2005 through March 2006.

10. F.E. Swalley, G.K. Platt, and L.J. Hastings, "Saturn V Low Gravity Fluid Mechanics Problems and their Investigation by Full-Scale Orbital Experiment," In Fluid Mechanics and Heat Transfer Under Low Gravity, Lockheed, June 1965.

11. Daniel J. Schieb, "Cryo Tracker Mass Gauging System Testing in a Large Scale Expendable Launch Vehicle LOX Tank Simulator," CEC 2006-04230, April 20, 2006. 


\begin{tabular}{|c|c|c|c|}
\hline \multicolumn{3}{|c|}{ REPORT DOCUMENTATION PAGE } & $\begin{array}{l}\text { Form Approved } \\
\text { OMB No. 0704-0188 }\end{array}$ \\
\hline \multicolumn{4}{|c|}{$\begin{array}{l}\text { Public reporting burden for this collection of information is estimated to average } 1 \text { hour per response, including the time for reviewing instructions, searching existing data sources, } \\
\text { gathering and maintaining the data needed, and completing and reviewing the collection of information. Send comments regarding this burden estimate or any other aspect of this } \\
\text { collection of information, including suggestions for reducing this burden, to Washington Headquarters Services, Directorate for Information Operations and Reports, } 1215 \text { Jefferson } \\
\text { Davis Highway, Suite 1204, Arlington, VA 22202-4302, and to the Office of Management and Budget, Paperwork Reduction Project (0704-0188), Washington, DC 20503. }\end{array}$} \\
\hline 1. AGENCY USE ONLY (Leave blank) & $\begin{array}{l}\text { 2. REPORT DATE } \\
\text { November } 2006\end{array}$ & 3. REPORT TYPE AI & $\begin{array}{l}\text { ID DATES COVERED } \\
\text { echnical Memorandum }\end{array}$ \\
\hline \multicolumn{3}{|c|}{$\begin{array}{l}\text { 4. TITLE AND SUBTITLE } \\
\text { Settled Cryogenic Propellant Transfer }\end{array}$} & \multirow{2}{*}{$\begin{array}{l}\text { 5. FUNDING NUMBERS } \\
\text { WBS 492994.05.01.01.03.02 }\end{array}$} \\
\hline \multicolumn{3}{|c|}{$\begin{array}{l}\text { 6. AUTHOR(S) } \\
\text { Bernard F. Kutter, Frank Zegler, Steve Sakla, John Wall, Greg Saks, Jack Duffey, } \\
\text { Josh Hopkins, and David J. Chato }\end{array}$} & \\
\hline \multicolumn{3}{|c|}{$\begin{array}{l}\text { 9. SPONSORING/MONITORING AGENCY NAME(S) AND ADDRESS(ES) } \\
\text { National Aeronautics and Space Administration } \\
\text { Washington, DC 20546-0001 }\end{array}$} & $\begin{array}{l}\text { 10. SPONSORING/MONITORING } \\
\text { AGENCY REPORT NUMBER } \\
\text { NASA TM-2006-214411 }\end{array}$ \\
\hline \multicolumn{4}{|c|}{$\begin{array}{l}\text { 11. SUPPLEMENTARY NOTES } \\
\text { Prepared for the 42nd Joint Propulsion Conference and Exhibit cosponsored by the AIAA, ASME, SAE, and ASEE, } \\
\text { Sacramento, California, July 9-12, 2006. Bernard F. Kutter, Frank Zegler, Steve Sakla, John Wall, and Josh Hopkins, } \\
\text { Lockheed Martin Space Systems Company, P.O. Box 179, Denver, Colorado 80201; Greg Saks and Jack Duffey, Lockheed } \\
\text { Martin Space Systems Company, } 4800 \text { Bradford Drive, Huntsville, Alabama 35807; and David J. Chato, NASA Glenn } \\
\text { Research Center. Responsible person, David J. Chato, organization code RTP, 216-433-7488. }\end{array}$} \\
\hline
\end{tabular}

\section{ABSTRACT (Maximum 200 words)}

Cryogenic propellant transfer can significantly benefit NASA's space exploration initiative. LMSSC parametric studies indicate that "Topping off" the Earth Departure Stage (EDS) in LEO with $20 \mathrm{mT}$ of additional propellant using cryogenic propellant transfer increases the lunar delivered payload by $5 \mathrm{mT}$. Filling the EDS to capacity in LEO with $78 \mathrm{mT}$ of propellants increases the delivered payload by $20 \mathrm{mT}$. Cryogenic propellant transfer is directly extensible to Mars exploration in that it provides propellant for the Mars Earth Departure stage and in-situ propellant utilization at Mars. To enable the significant performance increase provided by cryogenic propellant transfer, the reliability and robustness of the transfer process must be guaranteed. By utilizing low vehicle acceleration during the cryogenic transfer the operation is significantly simplified and enables the maximum use of existing, reliable, mature upper stage cryogenic-fluidmanagement (CFM) techniques. Due to settling, large-scale propellant transfer becomes an engineering effort, and not the technology development endeavor required with zero-gravity propellant transfer. The following key CFM technologies are all currently implemented by settling on both the Centaur and Delta IV upper stages: propellant acquisition, hardware chilldown, pressure control, and mass gauging. The key remaining technology, autonomous rendezvous and docking, is already in use by the Russians, and must be perfected for NASA whether the use of propellant transfer is utilized or not.

\begin{tabular}{|c|c|c|c|}
\hline \multicolumn{3}{|l|}{ 14. SUBJECT TERMS } & $\begin{array}{c}\text { 15. NUMBER OF PAGES } \\
15\end{array}$ \\
\hline
\end{tabular}



